\title{
EFEITO DO FÓSFORO SOBRE OS COMPONENTES DE PRODUÇÃO, ALTURA DAS PLANTAS E RENDIMENTO DE GRÃOS, EM TRIGO $\left({ }^{1}\right)$
}

\author{
OTÁVIO FRANCO DE OLIVEIRA, CARLOS EDUARDO DE OLIVEIRA CAMARGO ("), Seçäo \\ de Arroz e Cereais de Inverno, e VALDIR JOSUÊ RAMOS, Estação Experimental de \\ Itararé, Instituto Agronômico.
}

\section{RESUMO}

Foram instalados quatro experimentos utilizando os cultivares IAC-5 e Alondra-S-46, em solo recém-desbravado de acentuada pobreza em fósforo, na Estação Experimental de Itararé (SP), com - objetivo de estudar os efeitos da aplicação de $0,60,120,180$ e $240 \mathrm{~kg} /$ hectare de $P_{2} O_{5}$ sobre a produção de grãos, componentes de produção e altura das plantas de trigo. A produção de grãos dos dois cuitivares cresceu em função dos niveis de $\mathrm{P}_{2} \mathrm{O}_{\overline{7}}$ utilizados, apresentando o 'IAC-5' maior eficiência em relação ao 'Alondra-S-46'. A produção de grãos, comprimento da espiga, número de espiguetas por espiga, número de grāos por espiga, número de grãos por espigueta, peso de cem grãos e altura das plantas do cultivar IAC-5, aumentaram significativamente nos dois anos de experimentação até a dose de $60 \mathrm{~kg}$ de $\mathrm{P}_{2} \mathrm{O}_{\overline{-}}$ /hectare, sendo que deste nível para cima não se observaram diferenças significativas. Para o 'Alondra-S-46', verificaram-se respostas significativas até a dose de $60 \mathrm{~kg}$ de $\mathrm{P}_{2} \mathrm{O}_{\hat{n}}$ /hectare para comprimento da espiga, número de espiguetas por espiga, peso de cem grãos e altura em 1979 e 1980; para número de grãos por espiga e por espigueta, nos ensaios plantados em 1980, verificaram-se respostas significativas até a dose de $240 \mathrm{~kg}$ de $\mathrm{P}_{3} \mathrm{O}_{\overline{\mathrm{n}}} /$ hectare. Este cultivar somente mostrou aumento significativo na produção de grãos a partir da aplicação de $120 \mathrm{~kg}$

(1) Executado com recursos complementares do Acordo entre as Cooperativas de Produtores Rurais do Vale do Paranapanema e a Secretaria de Agricultura e Abastecimento, através do Instituto Agronômico. Recebido para publicação a 3 de junho de 1982.

(2) Com bolsa de suplementaçāo do CNPq. 
de $\mathrm{P}_{2} \mathrm{O}_{5}$ e somente em 1979. Não foram observadas respostas significativas à adubação com $P_{,} \mathrm{O}_{5}$ para número de espigas por metro linear e para o teor de fósforo (\%) na parte aérea, nos dois ancis, para os cultivares estudados. A produção de grãos do 'IAC-5' e 'Alondra-S-46' para as diferentes doses de $\mathrm{P}_{2} \mathrm{O}_{5}$ apresentou associações significativas com número de espiguetas por espiga, número de grãos por espiga, peso de cem grãos, altura de planta, número de espigas por metro linear e doses de $\mathrm{P}_{2} \mathrm{O}_{5} . \mathrm{O}$ 'IAC-5' apresentou associação significativa entre produção de grãos e número de grãos por espigueta, ao passo que, para o 'Alondra-S-46' esta associação não foi significativa. A associação entre produção de grãos e comprimento da espiga foi significativa apenas para o 'Alondra-S-46'. Associações entre doses de $\mathrm{P}_{2} \mathrm{O}_{5}$ e teores de fósforo na parte aérea das plantas foram altamente significativas para os dois cultivares.

\section{INTRODUÇÃO}

Não sendo o Brasil auto-suficiente na produção de trigo, as Instituições de Pesquisas que trabalham com este cereal têm-se esforçado em elevar-lhe o nível de produtividade. Assim, trabalhos têm sido feitos nas áreas de fertilidade de solo, tratos culturais e controle de doenças, visando alcançar este objetivo. As pesquisas mais abundantes, porém, são as relacionadas mais diretamente com a planta, isto é, com a constituição genética representada pelos componentes de produção: número de espigas por planta, comprimento da espiga, número de espiguetas por espiga, de grãos por espiga, de grãos por espigueta e peso de cem grãos.

Poucos estudos foram feitos visando saber os efeitos de diferentes níveis da adubação NPK nos componentes de produção do trigo. JOHNSON et alii (3), comparando os componentes de produção e outras características agronômicas de quatro variedades de trigo, diferindo em altura das plantas, concluíram que o cultivar mais produtivo foi um de porte baixo, que consistentemente produziu mais grãos por espiga, porém o peso dos grãos e o número de espigas por planta foi menor que nas outras variedades estudadas. $\mathrm{O}$ maior número de grãos por espiga dessa variedade foi associado com o maior número de espiguetas por espiga e maior número de grãos por espigueta.

FREY (2), trabalhando com aveia, relatou que os componentes de produção responderam diferentemente a fertilizantes nitrogenados e o número de grãos por espiga foi incrementado 30,45 e $50 \%$ quando se aplicaram, respectivamente, 20,40 e $80 \mathrm{~kg}$ de nitrogênio/hectare.

REITZ \& MYERS (5) afirmaram que a aplicação de fertilizantes fosfatados em trigo aumentou a produção de grãos e de palha.

Segundo FOLE \& GRIMM (1), o número de grãos por espiga foi o componente de produção que apresentou maior aumento com a aplicação de doses crescentes de $\mathrm{P}_{2} \mathrm{O}_{5}$, acompanhado pelo número de espigas por área, sendo pouco afetado o peso das sementes. 
No presente trabalho, procurou-se estudar o efeito da aplicação de níveis crescentes de fósforo, sobre a produção e seus componentes e sobre a altura das plantas, em dois cultivares diferentes de trigo.

\section{MATERIAL E MÉTODOS}

Quatro ensaios foram conduzidos na Estação Experimental de Itararé, no período 1979/80, em solo hidromórfico de altitude, série Coruja (4), recém-desbravado, apresentando elevada acidez, altos teores de matéria orgânica e acentuada pobreza em fósforo, conforme análise ( ${ }^{3}$ ) cujos resultados foram os seguintes:

Determinações

M. O. $\%$...

pH int .......

$\mathrm{Al}^{3+}\left({ }^{4}\right) \quad \ldots$.

$\mathrm{Ca}^{2+}\left({ }^{4}\right) \quad \ldots$

$\mathrm{Mg}^{2+}\left({ }^{4}\right) \ldots$

$\mathrm{K}\left({ }^{5}\right) \quad \ldots \ldots$

P ( $\left.{ }^{5}\right)$
1979

\section{7,7}

4,7

1,6

0,2

0,2

37

1
1980

11,7

4,5

2,1

0,3

0,2

50

2

Em cada ano, foram instalados dois experimentos, sendo utilizado o cultivar nacional IAC-5 em um e, no outro, o cultivar mexi. cano, Alondra-S-46, ambos de genealogia bastante diversa e, portanto, $\mathrm{com}$ adaptação diferente àquelas condições de solo.

o delineamento estatístico empregado em cada ensaio foi de blocos ao acaso com duas repetições. Sete linhas de $5 \mathrm{~m}$ de comprimenrio constituíram as parcelas, sendo úteis as três centrais. $O$ espaçamento entre linhas foi $0,20 \mathrm{~m}$, utilizando-se cinquienta sementes viáveis por metro linear de sulco.

Como fontes dos nutrientes, foram utilizados a uréia com $45 \%$ de $\mathrm{N}$, o superfosfato triplo com $46 \%$ de $\mathrm{P}_{2} \mathrm{O}_{5}$, o cloreto de potássio com $60 \%$ de $\mathrm{K}$ O e o gesso com $20 \%$ de $\mathrm{S}$. Estes fertilizantes foram aplicados no sulco antes do plantio na base de 60,30 e $40 \mathrm{~kg} /$ hectare de $\mathrm{N}, \mathrm{K} \cdot \mathrm{O}$ e $\mathrm{S}$.

Os tratamentos com $\mathrm{P}_{2} \mathrm{O}_{3}$, consistiram nas doses de $0,60,120$, 180 e $240 \mathrm{~kg} /$ hectare.

O primeiro ensaio foi plantado a 5 de abril e colhido a 14 de setembro de 1979, e. o segundo. foi plantado em área adjacente, a 27 de março, e colhido a 19 de setembro de 1980.

(3) Efetuada na Seção de Fertilidade do Solo, Instituto Agronômico.

(4) e.mg/100ml de T.F.S.A.

(5) $\mu \mathrm{g} / \mathrm{ml}$ de T.F.S.A. 
Para avaliação dos efeitos das diferentes doses de fósforo, utilizaram-se a produção de grãos, transformada em quilograma por hectare, a altura das plantas e os seguintes componentes de produção: número de espigas por metro linear, contando-se as espigas dentro de um metro linear de cada parcela; comprimento da espiga medida em centímetro do ponto de início da ramificação até seu ápice, excluindo-se a arista; número de espiguetas por espiga, o qual foi considerado como a soma total de todas as espiguetas da base ao ápice da espiga; número de grãos por espiga, contando-se o total de grãos em uma espiga; número de grãos por espigueta, calculando-se pelo quociente do número de grãos de uma espiga e número de espiguetas da espiga; peso de cem grãos, em gramas, considerando-se a média do peso de cinco amostras de cem grãos por parcela.

Para a determinação do comprimento da espiga, número de espiguetas por espiga, de grãos por espiga e de grãos por espigueta, foram colhidas dez espigas de cada parcela por ocasião da maturação das plantas.

Outro parâmetro avaliado foi a altura das plantas de cada cultivar, medida em centímetro do nível do solo até o ápice da espiga, excluindo-se as aristas. Por ocasião do florescimento, coletaram-se, da bordadura, dez plantas por parcela, excluindo-se as raízes, para análise química de fósforo, segundo critério estabelecido pela Seção de Química Analítica do Instituto Agronômico.

$\mathrm{O}$ teste $\mathrm{F}$ foi utilizado para testar os niveis de significância, e as médias foram comparadas pelo teste de Tukey a $5 \%$.

Foram feitas correlações simples entre produção de grãos com doses de $\mathrm{P}_{2} \mathrm{O}_{5}$, altura das plantas e componentes de produção para os cultivares IAC-5 e Alondra-S-46, considerando-se em conjunto os resultados dos experimentos plantados em 1979 e 1980.

Foram calculadas, para os dois cultivares, as equaçōes da regressão linear, considerando o teor de fósforo na planta, em porcentagem, em função da quantidade de $\mathrm{P}_{2} \mathrm{O}_{5}$ aplicada em quilograma/hectare.

\section{RESULTADOS E DISCUSSÃO}

\subsection{Ensaios com o cultivar IAC-5}

Os resultados médios e as análises de variância da produção, componentes de produção, teores de fósforo na parte aérea das plantas e altura das plantas do cultivar IAC-5, em 1979, são apresentados no quadro 1. 


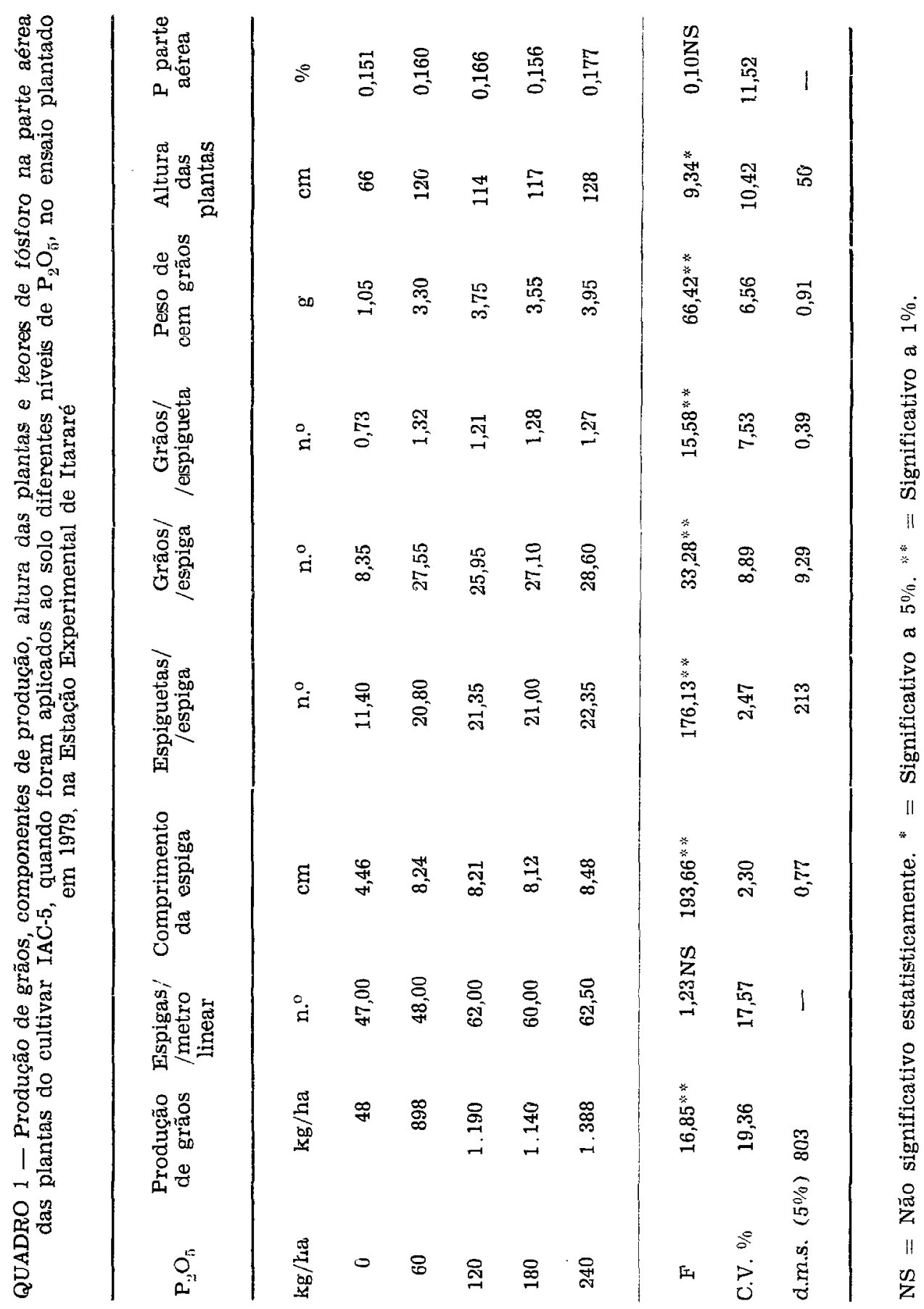


Foram observados efeitos altamente significativos de $\mathrm{P}_{2} \mathrm{O}_{\overline{5}}$ para a piodução de grãos, comprimento da espiga, número de espiguetas por espiga, de grãos por espiga, de grãos por espigueta e peso de cem grãos. Quanto à altura, as plantas responderam significativamente ao nível de 5\%. Não houve diferença significativa entre os tratamentos em relação ao número de espigas por metro linear e teores de fósforo em porcentagem na parte aérea das plantas. $O$ resultado obtido com o número de espigas por metro linear era esperado, porque este componente de produção é consequiência do maior ou menor perfilhamento das plantas, o qual, por sua vez, é mais influenciado pela adubação nitrogenada do que pela aplicação de fósforo (2).

Utilizando-se do teste de Tukey ao nível de $5 \%$, verificou-se que quando foram aplicados $60,120,180$ e $240 \mathrm{~kg} /$ ha de $\mathrm{P}_{2} \mathrm{O}_{5}$, produção de grãos, comprimento da espiga, número de espiguetas por espiga, de grãos por espiga, de grãos por espigueta, peso de cem grãos e altura das plantas diferiram significativamente do tratamento testemunha ( $0 \mathrm{~kg}$ de $\mathrm{P} . \mathrm{O} \% /$ hectare), porém não foram encontradas diferenças significativas para as mesmas características entre os tratamentos adubados com $\mathrm{P}_{2} \mathrm{O}_{5}$.

Estudos efetuados com os dados de 1980 confirmaram os resultados do ano anterior (Quadro 2). Considerando-se as médias da produção de grãos e da altura das plantas referentes à dose de $60 \mathrm{~kg}$ / hectare de $\mathrm{P}_{2} \mathrm{O}_{\bar{n}}$, verificou-se, pelo teste de Tukey, que elas não diferiram significativamente daquelas onde năo foi aplicada adubação fosfatada. Essa significância, entretanto, foi observada quando se comparou a primeira dose $\left(60 \mathrm{~kg} /\right.$ hectare de $\left.\mathrm{P}_{2} \mathrm{O}_{\tilde{n}}\right)$ com a dose máxima $(240 \mathrm{~kg} /$ hectare de $\left.\mathrm{P}_{2} \mathrm{O}_{5}\right)$, no caso da produçăo.

\subsection{Ensaios com o cultivar Alondra-S-46}

Os resultados médios da produção de grãos, componentes de produção, altura das plantas e teores de fósforo em porcentagem na narte aérea das plantas, do cultivar Alondra-S-46, plantado em 1979, com suas respectivas análises de variância, encontram-se no quadro 3.

Notou-se efeito altamente significativo de doses de $\mathrm{P}_{2} \mathrm{O}_{;}$em relacão à producão de grãos, peso de cem grãos e altura das plantas. Efeitos significativos foram obtidos para o comprimento da espiga e número de espiguetas por espiga nas diferentes doses de $\mathrm{P}_{2} \mathrm{O}_{5}$. $\mathrm{O}$ número de espigas por metro linear e de grãos nor espiga e os teores de fósforc em porcentagem na parte aérea das plantas não apresentaram respostas significativas em relação aos tratamentos utilizados.

Empregando-se o teste de Tukey ao nível de 5\%. verificou-se que as médias do comprimento da espiga, do número de espiguetas por espiga, do peso de cem grãos e da altura, para os tratamentos que 


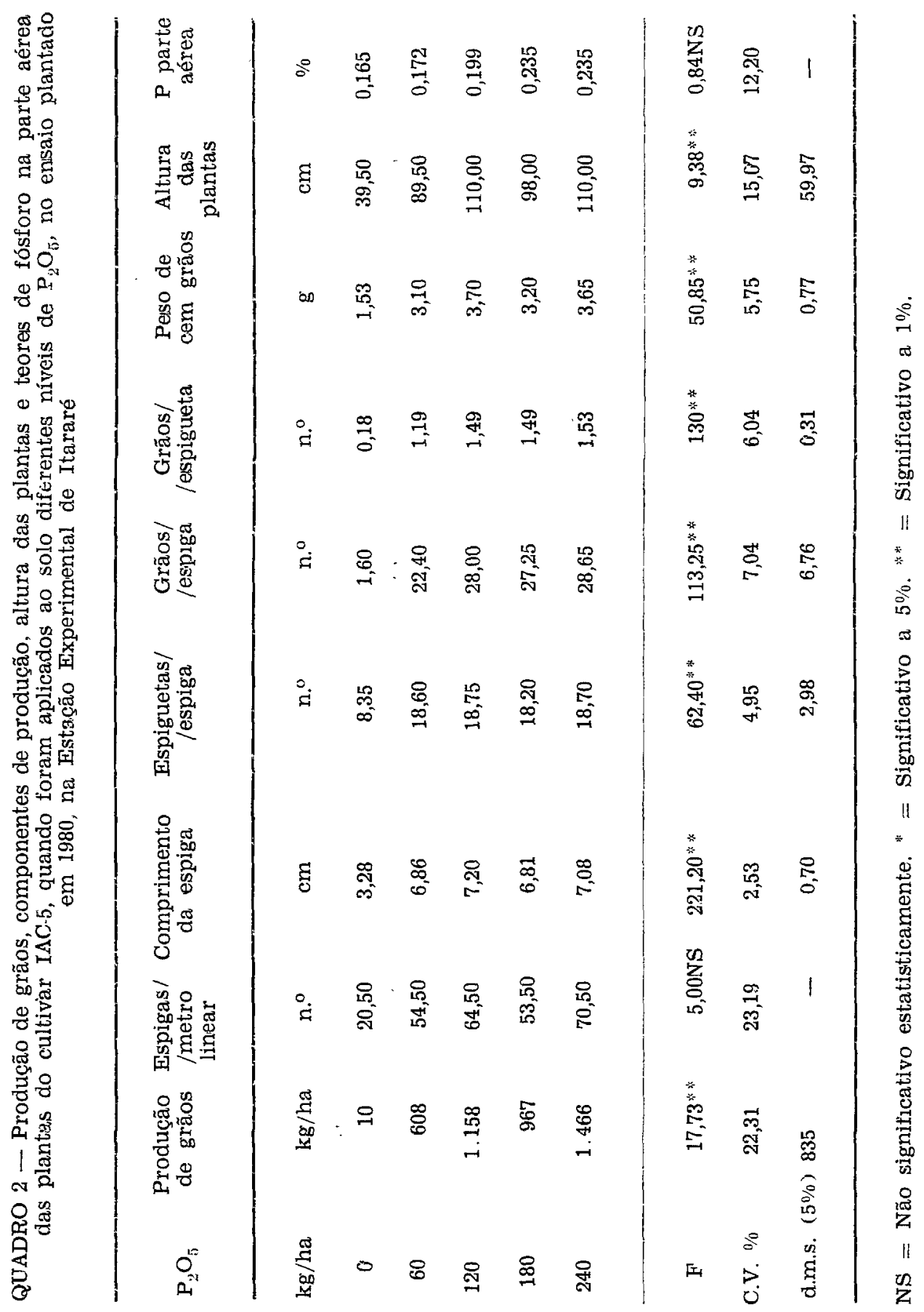




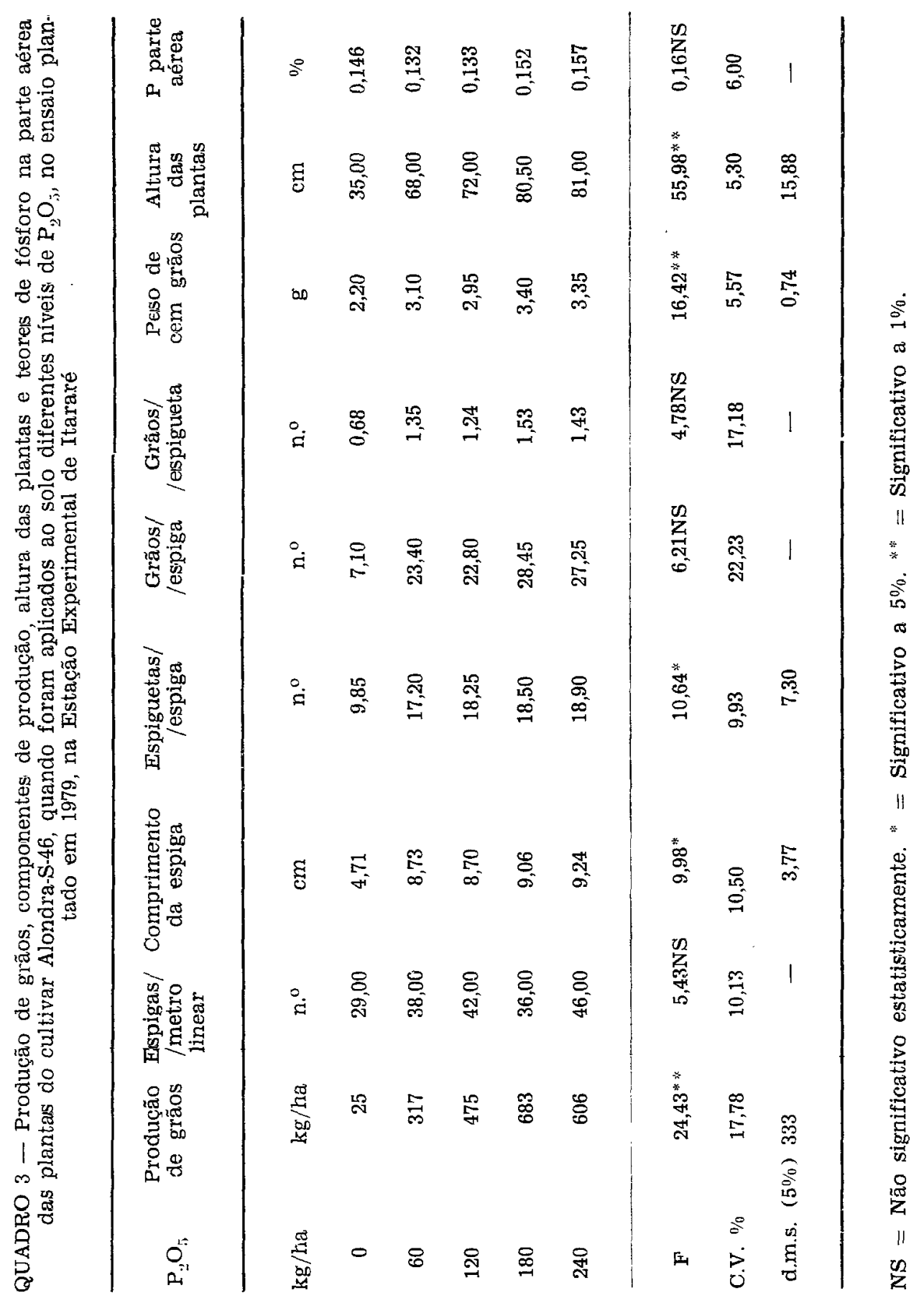


receberam de 60 a $240 \mathrm{~kg} /$ hectare, diferiram da testemunha $(0 \mathrm{~kg}$ de $\mathrm{P}_{2} \mathrm{O}_{5} /$ hectare), embora não diferissem entre si.

Considerando-se a producão de grãos obtida com a dose de $60 \mathrm{~kg} /$ hectare de $\mathrm{P}_{2} \mathrm{O}_{5}$, notou-se que ela não diferiu significativamente da testemunha; as produções obtidas com as doses de 120,180 e $240 \mathrm{~kg}$ / hectare de $\mathrm{P}_{2} \mathrm{O}_{3}$ não diferiram entre si, porém diferiram da produção obtida no tratamento sem adubação fosfatada.

Os resultados médios e as análises de variância da produção de grãos, componentes de produção, altura das plantas e teor de fósforo na parte aérea das plantas do cultivar Alondra-S-46, obtidos em 1980, são apresentados no quadro 4 .

Observou-se efeito altamente significativo da adubação fosfatada para comprimento da espiga, número de espiguetas por espiga, de grãos por espiga, de grãos por espigueta e sobre a altura das plantas. O peso de cem grãos respondeu significativamente ao nível de 5\% aos crescentes niveis de $\mathrm{P}_{2} \mathrm{O}_{5}$ aplicados. Não houve diferenças significativas entre os tratamentos em relação à produção de grãos, ao número de espigas por metro linear e ao teor de fósforo em porcentagem na parte aérea dás plantas.

A produção de grãos em 1980 foi inferior àquela obtida em 1979, devido às condiçōes climáticas adversas ocorridas no ciclo da cultura. O número de espigas por metro linear e o teor de fósforo na parte aérea das plantas não diferiram entre os tratamentos com diferentes níveis de $\mathrm{P}_{2} \mathrm{O}_{3}$, aplicados no solo.

Aplicando-se o teste de Tukey para o comprimento da espiga, número de espiguetas por espiga, número de grãos por espiga, número de grãos por espigueta e altura de plantas, notou-se que os tratamentos adubados com fósforo, embora não diferissem entre si, superaram a testemunha.

\subsection{Ccrrelações gerais da produção de grãos}

As associações simples entre os dados da produção e os componentes de produção, a altura de plantas e as doses de $\mathrm{P}_{2} \mathrm{O}_{\tilde{n}}$, para cada um dos cultivares estudados, encontram-se no quadro 5 . Os resultados revelaram coeficientes altamente significativos entre a produção do cultivar IAC-5 com o número de espigas por metro linear, comprimento da espiga, número de espiguetas por espiga, de grãos por espiga, de grãos por espigueta, peso de cem grãos, altura das plantas e doses de $\mathrm{P}_{2} \mathrm{O}_{\text {i. }}$. Por outro lado, a produção do cultivar Alondra-S-46 apresentou coeficientes de correlação altamente significativos para o comprimento da espiga, número de espiguetas por espiga, de grãos por espiga, peso de cem grãos e altura das plantas, significativos ao nível de $5 \% \mathrm{com}$ o 


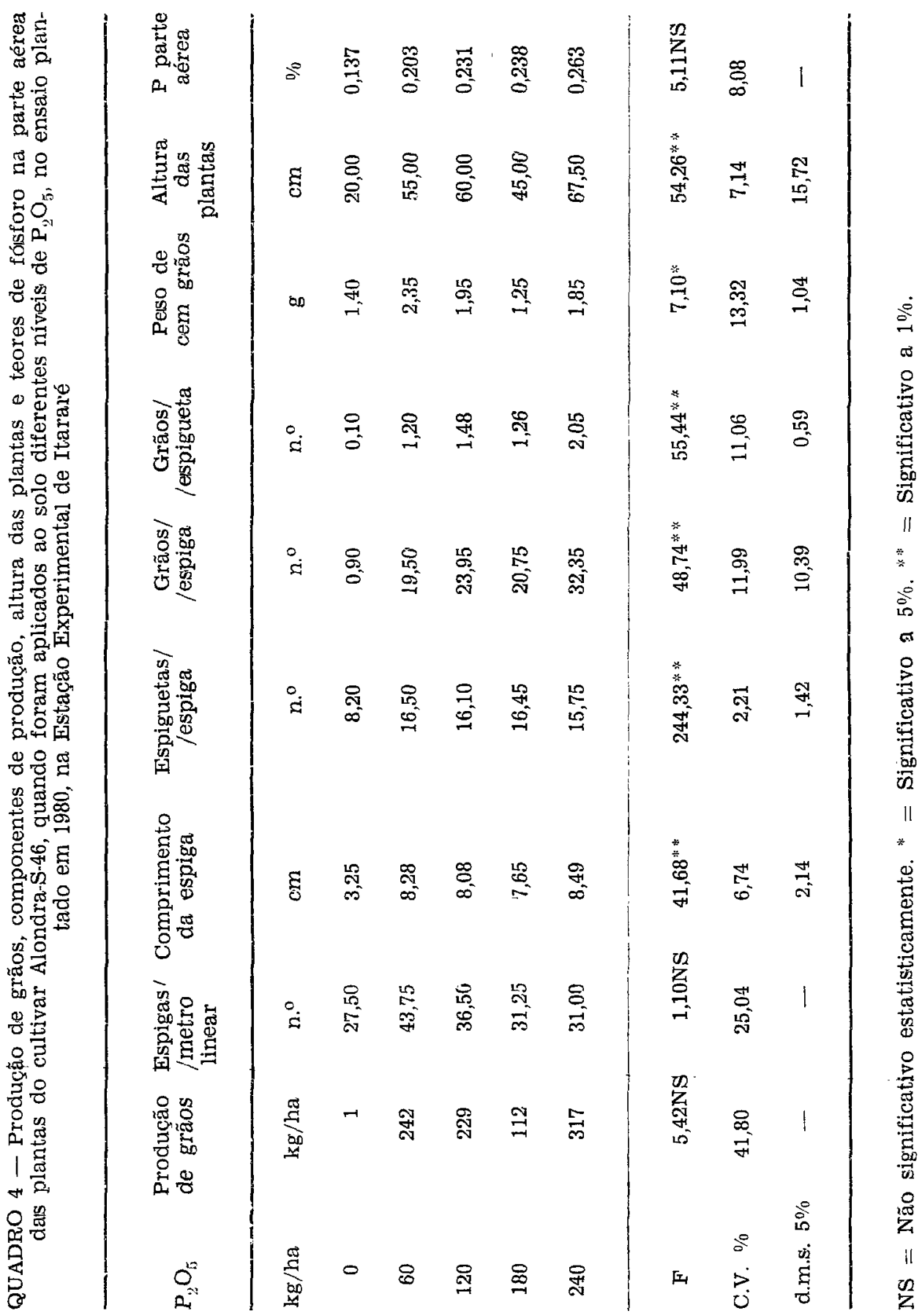


número de espigas por metro linear e doses de $\mathrm{P}_{2} \mathrm{O}_{5}$. $\mathrm{O}$ número de grãos por espigueta não se correlacionou significativamente com a produção de grãos, para esse cultivar.

QUADRO 5 - Correlações simples, utilizando-se as médias de 1979 e 1980 entre a produção de grãos e os componentes de produção, altura das plantas e doses de $\mathrm{P}_{2} \mathrm{O}_{5}$ dos cultivares de trigo IAC-5 e Alondra-S-46, nos ensaios empregando diferentes niveis de $\mathrm{P}_{2} \mathrm{O}_{5}$ plantados na Estação Experimental de Itararé

Caracteres correlacionados

Coeficientes de correlação

com a produção de grãos

IAC-5 Alondra-S-46

Número de espigas/metro linear

$0,8600 \div$

$0,6709^{*}$

Comprimento da espiga

$0,8701 \%$

$0,7929 \%$

Número de espiguetas/espiga

$0,8799 \div$

$0,8165^{* * *}$

Número de grãos/espiga

$0,9271^{* *}$

$0,7507 \div$

Número de grãos/espigueta

$0,8560 \%$

0,6082

Peso de cem grãos

0,9506 \%

$0,8429 \%$

Altura das plantas

$0,9108 * *$

$0,9314^{* *}$

Doses de $\mathrm{P}_{2} \mathrm{O}_{5}$

$0,8989 \div$

$0,6549^{\text {t }}$

* Significativo ao nível de $5 \%{ }^{* *}=$ Significativo ao nível de $1 \%$.

Na figura 1, são apresentados os teores de fósforo na parte aérea das plantas em função das doses crescentes de $\mathrm{P}_{2} \mathrm{O}_{\tilde{\mathbf{v}}}$ aplicadas no solo, para as médias dos ensaios plantados em 1979 e 1980 , usando-se os cultivares IAC-5 e Alondra-S-46. Verificou-se maior eficiência do IAC-5 em retirar fósforo do solo quando este elemento não estava presente na adubação. As porcentagens elevadas desse elemento na parte aérea das plantas do 'Alondra-S-46' deveu-se, em parte, ao menor desenvolvimento das plantas concentrando o fósforo nos seus tecidos, enquanto o 'IAC-5', sendo mais adaptado às condições de solo da região, apresentou maior desenvolvimento vegetativo, diluindo, assim, o teor de fósforo do tecido. Verifica-se, porém, que associações entre doses de $\mathrm{P}_{2} \mathrm{O}_{5}$ aplicadas no solo e teores de fósforo na parte aérea das plantas foram altamente significativas para os dois cultivares. 


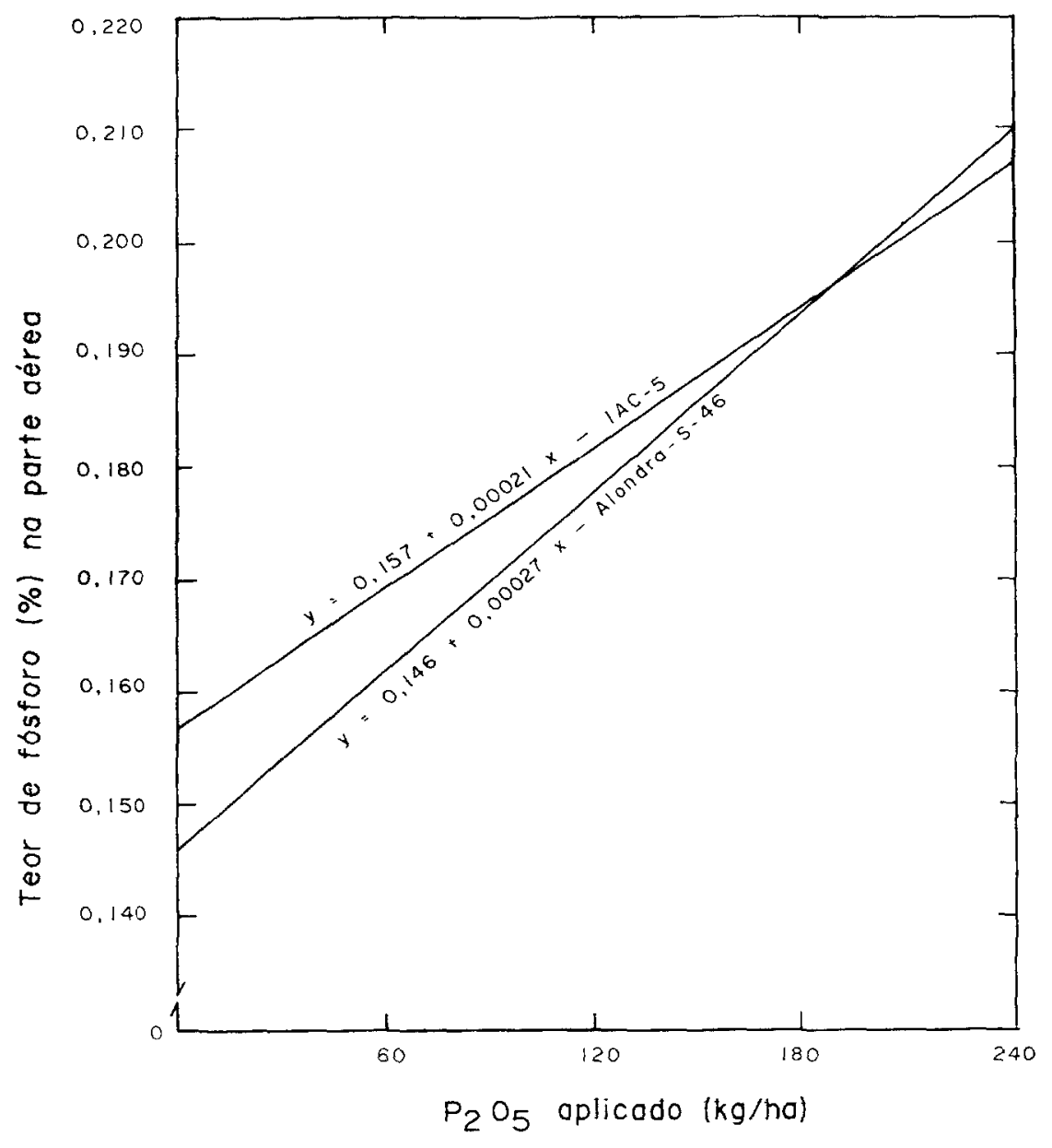

FIGURA 1 - Regressão das médias do teor de fósforo (\%) na parte aérea das plantas dos cultivares de trigo IAC-5 e Alondra-S-46, em função das doses crescentes de $\mathrm{P}_{2} \mathrm{O}_{5}$ aplicados no solo $(\mathrm{kg} / \mathrm{ha})$, considerando-se as médias dos ensaios plantados em 1979 e 1980 no Estação Experimental de Itararé. 


\section{CONCLUSÕES}

O estudo dos efeitos de doses crescentes de fósforo na produção de grãos, altura das plantas e componentes de produção de dois cultivares de trigo estudados por dois anos em Itararé (SP), permitiram tirar as seguintes conclusões:

a) A produção de grãos do cultivar IAC-j foi superior à do Alondra-S-46 em todos os níveis de $\mathrm{P}_{2} \mathrm{O}_{5}$ aplicados ao srlo.

b) O 'IAC-5' mostrou-se mais eficiente quando comparado com o 'Alondra-S-46' no aproveitamento do fósforo aplicado e ao existente no solo.

c) A produção de grãos, comprimento da espiga, número de espiguetas por espiga, de grãos por espiga, de grãos por espigueta, peso de cem grãos e altura das plantas do cultivar IAC-5 aumentaram significativamente com a aplicação da adubação fosfatada, considerando conjuntamente os dados dos anos de 1979 e 1980.

d) Para o cultivar Alondra-S-46 nos dois anos estudados, o comprimento da espiga, o número de espiguetas por espiga, peso de cem grãos e altura das plantas aumentaram sịnificativamente com a adubação fosfatada.

e) A produção de grãos do 'IAC-5' apresentou associações altamente significativas com o número de espigas por metro linear, comprimento da espiga, número de espiguetas por espiga, de grãos por espıga, de grãos por espigueta, peso de cem grãos, altura das plantas e doses de $\mathrm{P}_{2} \mathrm{O}_{\overline{5}}$, considerando-se a média de 1979 e 1980.

f) A produção de grãos do 'Alondra-S-46' apresentou associações altamente significativas com o comprimento da espiga, número de espiguetas por espiga, de grãos por espiga, peso de cem grãos e altura das plantas; associaçōes significativas com o número de espigas por metro linear e doses de $\mathrm{P}_{2} \mathrm{O}_{\bar{n}}$; e associações não-significativas com o número de grãos por espigueta, considerando-se as médias de $1979 \mathrm{e}$ 1980.

g) Associações entre doses de $\mathrm{P}_{2} \mathrm{O}_{5}$ e teores de fósforo na parte aérea das plantas foram altamente significativas para os dois cultivares.

\section{SUMMARY}

\section{EFFECT OF PHOSPHORUS ON YIELD COMPONENTS, PLANT HEIGHT AND GRAIN YIELD, IN WHEAT CULTIVARS}

Four experiments using the wheat cultivars: IAC-5 and Alondra-S-46 were carried out at Itarare Experimental Station in an acid soil showing low levels of phosphorus during the years of 1979 and 1980. The treatments consisted of five 
levels of $\mathrm{P}_{2} \mathrm{O}_{5}$ per hectare namely $0,60,120,180$ and $240 \mathrm{~kg}$. Grain yield increased with applied phosphorus for the two cultivars but IAC-5 showed higher yield and higher phosphorus efficiency in comparison with Alondra-S-46. Grain yield, spike lenght, number of spikelets per spike, number of kernel per spike, number of kernel per spikelet, 100 kernel weight and plant height for the cultivar IAC-5 when levels of phosphorus were applied showed values significantly superior when compared with check. Considering the cultivar Alondra-S-46 the same conclusions were obtained for the following characteristics: head lenght, number of spikelets per spike, 100 kernel weight and plant height. The cultivar IAC-5 presented grain yield for the different levels of $\mathrm{P}_{2} \mathrm{O}_{5}$ applied in the soil highly associated with all yield components under study, with plant height and with the amounts of $\mathrm{P}_{2} \mathrm{O}_{5}$ applied in the soil. Considering the cultivar Alondra-S-46 grain yield was highly correlated with head lenght, number of spikelets per spike, number of kernel per spike, 100 kernel weight and plant height, correlated with number of heads per linear meter and $\mathrm{P}_{2} \mathrm{O}_{5}$ levels applied in the soil and no association between grain yield and number of grain per spikelets was observed. Associations between levels $\mathrm{P}_{2} \mathrm{O}_{5}$ applied to the soil and phosphorus concentrations in the tops were highly significant for the two wheat cultivans under study.

\section{REFERÊNCIAS BIBLIOGRÁFICAS}

1 FOLE, D. A. \& GRIMM, S. S. Efeito do $P$ aplicado sobre os componentes da produção de trigo. Agronomia Sulriograndense, Porto Alegre, 9(1):47-56. 1973 .

2. FREY, K, J. Yield components in oats. II. The effect of nitrogen fertili zation. Agronomy Journal, 51(10):605-608, 1959.

3 JOHNSON, V. A.; SCHMIDT, J. W.; MEKASHA, W. Comparison of yield components and agronomic characteristics of four winter wheat varieties differing in plant height. Agronomy Journal, 58:438-441, 1966.

4 OLIVEIRA, J. B.; VALADARES, J. M. A. S.; ROTTA, C. L. Levantamento pedológico detalhado da Estação Esperimental de Itararé, SP. Bragantia. Campinas, 35:295-333, 1976.

5 REITZ, L. P. \& MYERS, H. E. Response of wheat varieties to applications of superphosphates fertilizers. Journal of American Society of Agronomy, 36 (11) :928-936, 1944 . 